\title{
Solving Daniel Bernoulli's St Petersburg Paradox: The Paradox which Is Not and Never Was $^{1}$
}

\section{Robert W Vivian}

School of Economic and Business Sciences, University of the Witwatersrand

\section{ABSTRACT}

It has been accepted for over 270 years that the expected monetary value (EMV) of the St Petersburg game is infinite. Accepting this leads to a paradox; no reasonable person is prepared to pay the predicted large sum to play the game but will only pay, comparatively speaking, a very moderate amount. This paradox was 'solved' using cardinal utility. This article demonstrates that the EMV of the St Petersburg game is a function of the number of games played and is infinite only when an infinite number of games is played. Generally, the EMV is a very moderate amount, even when a large number of games is played. It is of the same order as people are prepared to offer to play the game. There is thus no paradox. Cardinal utility is not required to explain the behaviour of the reasonable person offering to play the game.

JEL D81

Samuelson (1977: 24) pointed out that 'the veritable who's who ${ }^{2}$ in probability and the social sciences' have been connected with Bernoulli's (1954/1738) St Petersburg Paradox ${ }^{3}$. Indeed, few would dispute the correctness of Bernstein's $(1998,100)$ observation that Bernoulli's '...paper is one of the most profound documents ever written'. Besides those who specifically considered the paradox, the utility solution to the paradox is implicitly accepted by those who apply cardinal utility notions to problems of decision making under conditions of risk and uncertainty. This has produced a formidable body of literature ${ }^{4}$.

The St Petersburg Paradox has thus been enormously influential. The purpose of this article is to demonstrate that contrary to the accepted view, the $\mathrm{St}$ Petersburg game does not lead to a paradox at all.

\section{The St Petersburg Game}

The background to the St Petersburg game ${ }^{5}$ is now ${ }^{6}$ well-known and it is not 
necessary to repeat it here in any detail. For ease of reference only a brief overview is given.

Attempts have been made for a long time to develop decision criteria to assist in the decision making process or to find theories ${ }^{7}$ explaining why people make the decisions they do when facing conditions of risk and uncertainty. The earliest and most well-known criterion is the expected monetary value (EMV) criterion ${ }^{8}$, the formulation of which is credited ${ }^{9}$ to Pierre de Fermat (1601-1665) and Blaise Pascal (1623-1662). According to this criterion a person faced with this kind of decision would or should choose the path involving uncertainty, if it has the most advantageous EMV.

Daniel Bernoulli (1738) attempted to demonstrate that this criterion did not in fact explain the behaviour of a reasonable person ${ }^{10}$ under these circumstances. $\mathrm{He}$ used a number of problems including the poor fellow problem and the $\mathrm{St}$ Petersburg game ${ }^{11}$ to support his hypothesis. He then went on to suggest an alternative theory. His new theory was based on the notion of marginal decreasing value of wealth ${ }^{12}$. This today, in its developed form is the expected utility value (EUV) criterion or expected utility value hypothesis.

The St Petersburg game goes like this. Peter offers Paul an opportunity to take part in a game of chance where a coin is flipped and if a head appears (with an $a$ priori probability of $1 / 2$ ), Paul receives $\$ 1$ (ie $\left.\$ 2^{0}\right)^{13}$. If it does not appear, the game continues. If the head appears after the second flip (with an a priori probability of $1 / 2^{2}$ ), Paul receives $\$ 2$ (ie $\$ 2^{1}$ ) and if not, the game continues in this fashion, until such time as a head appears (if ever) whereupon the game terminates and Paul can take his winnings. It is conceptually possible for any game to continue to infinity. The probability of the game terminating at the $1^{\text {th }}$ flip of the coin is $1 / 2^{\mathrm{i}}$ with a corresponding payout of $\$ 2^{\mathrm{i}-1}$.

The simple question to be answered is how much should, a reasonable person, the proverbial Paul be prepared to pay to play the game? As a rule-of-thumb, the answer should be of the same order as the EMV of the game ${ }^{14}$. From Bernoulli (1738) to Aase (2001) it has been accepted that the EMV of the game is infinite. In other words accepting the EMV as a rule-of-thumb guide, a reasonable man should be prepared to pay an exceptionally large sum to play the game.

The traditional derivation is as follows.

The game can have any payout from the following infinite range of payouts $\left(\mathrm{C}_{\mathrm{i}}\right.$ expressed in dollars); 
$2^{0}, 2^{1}, 2^{2}, 2^{3}, \ldots 2^{\mathrm{i}-1} \ldots$

each with a corresponding a priori probability $\left(\mathrm{p}_{\mathrm{i}}\right)$ associated with it, indicated as follows:

$2^{-1}, 2^{-2}, 2^{-3}, 2^{-4} \ldots 2^{-\mathrm{i}} \ldots$

And since

$E M V=\sum_{i=1}^{i=\infty} p_{i} C_{i}$

it follows from series (1), (2) and equation (3) that, expressed in dollars, the EMV is determined as shown in Table 1

Table 1 Traditional solution of the St Petersburg game

\begin{tabular}{||l|c|c|c|c|c|c|c|c|c||}
\hline \multicolumn{1}{|c|}{ Term } & $\mathbf{T}_{\mathbf{1}}$ & $\mathbf{T}_{\mathbf{2}}$ & $\mathbf{T}_{\mathbf{3}}$ & $\mathbf{T}_{\mathbf{4}}$ & $\cdots$ & $\mathbf{T}_{\mathbf{i}}$ & $\cdots$ & $\mathbf{T}_{\mathbf{8}}$ & $\mathbf{T o t a l s}$ \\
\hline Payout $\left(\mathrm{C}_{\mathrm{i}}\right)$ & $2^{0}$ & $2^{1}$ & $2^{2}$ & $2^{3}$ & $\ldots$ & $2^{\mathrm{i}-1}$ & $\ldots$ & 8 & $\mathrm{Na}$ \\
\hline Probability $\left(\mathrm{p}_{\mathrm{i}}\right)$ & $2^{-1}$ & $2^{-2}$ & $2^{-3}$ & $2^{-4}$ & $\cdots$ & $2^{-\mathrm{i}}$ & $\ldots$ & 0 & 1 \\
\hline $\begin{array}{l}\text { Contribution } \\
\text { to EMV }\left(\mathrm{p}_{\mathrm{i}} \mathrm{x} \mathrm{C}_{\mathrm{i}}\right)\end{array}$ & $2^{-1}$ & $2^{-1}$ & $2^{-1}$ & $2^{-1}$ & $2^{-1}$ & $2^{-1}$ & $2^{-1}$ & $\ldots$ & $\begin{array}{c}\text { EMV }= \\
? \mathrm{p}_{\mathrm{i}} \mathrm{xC} \\
=8\end{array}$ \\
\hline
\end{tabular}

or the $\mathrm{EMV}=8$.

A number of points about the traditional solution of the EMV should be noted. The EMV is infinite because the series consists of an infinite number of terms each of constant value, in this example $\$ 1 / 2$. The sum of this infinite series of finite numbers is infinite

An infinite amount can be an issue for another reason. As the game continues, the payouts become increasing large, tending to infinity. It is possible to confuse the infinity which comes from the sum of the series and infinity of a very large payout. These two infinities are more often than not confused. The paradox concerns Paul's decision vis-à-vis the EMV $=8$, not Paul's decision vis-à-vis final large payout. Even for very large payouts, according to the traditional derivation ${ }^{15}$, the contribution of each of payouts to the EMV is still the same constant ${ }^{16}$. 
Concluding that the EMV of the game is infinite, empirical evidence indicates that no reasonable person in the position of Paul will risk a substantial amount (let alone an infinite amount) to play the game. Numerous empirical ${ }^{17}$ tests indicate that in general people will not risk more than $\$ 12$ - $\$ 13$ to play the game, and in the vast majority of cases a sum much less than this. Therein lies the paradox. The EMV predicts that a reasonable person should be prepared to risk a very large amount to play the game, and generally no fault can be found with the EMV decision criterion which is still the most widely used decision criterion and no-one can fault the reasonable person for not being prepared to risk a large amount to play the game. Both are seemingly correct and no completely satisfactory ${ }^{18}$ explanation has been found to reconcile these contradictory conclusions - hence the apparent paradox.

\section{DETERMINING THE EMV THE ST PETERSBURG GAME}

It will now be shown that the traditional determination of the EMV is only correct as a special case where the game is played an infinite number of times.

\subsection{A single game}

First, the position of a single game ${ }^{19}$ is considered.

It seems to me the source of the paradox stems from the irrational assumption that the EMV can be applied equally when a large number of games are played or when a single game is played. This irrational assumption ignores the Law of Large Numbers. Since the EMV by definition, is concerned with the average payouts of a number of games, the EMV is of little assistance when a single game is played $^{20}$.

If the game is played only once, there will be one outcome (?) taken from the following series of possible outcomes, shown with their respective probabilities of occurring:

$?=\left[\left(2^{0} ; 1 / 2^{1}\right)\right.$ or $\left(2^{1} ; 1 / 2^{2}\right)$ or $\left(2^{2} ; 1 / 2^{3}\right)$ or $\ldots$ or $\left.\left(2^{i} ; 1 / 2^{i-1}\right) \ldots(8 ; 0)\right]$

This is an infinite series of mutually exclusive outcomes $1,2,4,8 \ldots$ with corresponding probabilities of 0,$5 ; 0,25 ; 0,125 ; 0,0625 \ldots)$. To accept the traditional view that the EMV of a single game is infinite or a large number is to ignore the possibility of any of the lower, high probability outcomes. This is a very unrealistic assumption.

When a single game is played, the EMV is of little use and an alternative 
approach is needed. It must be decided how much should Paul be prepared to pay to play this single game with this range of outcomes and probabilities?

Although the EMV may not, where a single game is played be of much assistance to Paul, Arrow $(1974,415)$ correctly points out that probabilities are relevant, even when a single game is played. He wrote, '[w]hile it may seem hard to give justification for using probability statements when the event occurs only once ... the contrary position [that probability statements are irrelevant] also seems difficult to defend.' It is not the EMV which is important when playing a single game but the probability of the outcome. The choice facing Paul can be likened to Paul placing his hand in a very large barrel filled with millions of small, marked balls and he can select only one. Fifty percent of the balls are marked $\mathrm{T}_{1}$ (paying $\$ 1$ ), twenty-five percent are marked $\mathrm{T}_{2}$ (paying $\$ 2$ ), twelve and a half per cent are marked $\mathrm{T}_{3}$ (paying $\$ 4$ ), and so forth. Thus 93,75 per cent of the balls will pay an amount of $\$ 8$ or less. The question then becomes, which single ball does he think he will draw and how much should he be prepared to pay for the right to draw this single ball?

Paul as noted is the proverbial reasonable man. He is not the most pessimistic nor most optimistic; not the wisest nor the most foolish. Based on probabilities it is suggested that he will not wager much in excess of $\$ 8$ to play this single game. In general he does not expect to win more than this by playing a single game. If this is so, he should not be prepared to loose more than this. At $\$ 8$ there is a 93.75 percent possibility that he will win $\$ 8$ or less and a 6.25 per cent that he will win in excess of $\$ 8$. He would be an optimist to pay an amount in excess of $\$ 8$. If a range indicating what people generally will wager to play a single game, rather than a single figure of $\$ 8$ is selected, the range is between $\$ 4$ to $\$ 32$. This range is in line with the collective wisdom of history ${ }^{21}$.

\subsection{The EMV of M games}

As indicated it is doubtful if the EMV is meaningful when only a single game is played so, multiple games are now considered. Multiple games must be considered for another reason. The issue is not only what is Paul prepared to pay for his ticket, but also what should Peter be prepared to accept to allow Paul to take part in the game. Logically if Paul is asked how much would he be prepared to pay to play the game, his answer will be, 'As little as possible preferably nothing. ${ }^{22}$ It is Peter after all who carries the risk. If Peter accepts $\$ 8$ for the ticket, then Paul knows the extent of his possible loss, $\$ 8$. It is Peter who does not know the extent of his liability until the game or all the games have ended. Although Paul has only one ticket, seen from Peter's perspective, if for example he is a casino owner, prepared to accept wagers on the $\mathrm{St}$ Petersburg game there may, over a period of time be millions of other tickets about which he must be concerned. So Peter needs to know what is likely to 
happen if he accepts $\$ 8$ per game and $\mathrm{M}$ games are played.

Assume then that $\mathrm{M}$ games are played. This assumption carries with it a number of implications which may not be obvious. Firstly, if $\mathrm{M}$ games are played there are only $\mathrm{M}$ outcomes, not an infinite number of outcomes. Each game can have only one outcome. Conceptually one of these could continue to infinity ${ }^{23}$. Secondly the mere statement that $\mathrm{M}$ games will be played implies that all games do in fact terminate, ie that one of the $M$ games does not continue to infinity. This accords with reality ${ }^{24}$ and theory ${ }^{25}$. The fact that a game may go to infinity does not mean that a game does go to infinity. What is not known is where each or any of the $\mathrm{M}$ games end. Thirdly despite the fact that all the games end, no limit is placed on any single game. Particularly no limit is placed on the length of time that any game may last ${ }^{26}$ or on the magnitude of the payout. If a game happens to go to infinity, Peter must live with that risk.

Once it is accepted that the games are played a multiple number of times, the mathematical nature of the problem becomes clear. Peter must find a way of determining the EMV of a series of terminating games, but the point of termination is not known beforehand. If Peter is prepared to accept $\$ 8$ per game, millions of Pauls may be prepared to play games for that amount. Will Peter be able to pay the millions of Pauls out of the $\$ 8$ per game he is prepared to accept?

Once the problem is correctly stated, it is not difficult to solve. Assume the game is played $\mathrm{M}=2{ }^{\mathrm{k}}$ times. If this generalised approach is adopted then $\mathrm{M}$ (or k) can be varied from 1 to infinity. In this manner all possible numbers of games are catered for, including $\mathrm{M}=\infty$. The methodology for solving the problem was suggested by Bernoulli $(1954 / 1738,32)$ himself. The solution setout in this paper could have been arrived at in 1738. Bernoulli pointed out that the number of games $\left(\mathrm{n}_{\mathrm{i}}\right)$ which terminate at the first flip of the coin (first term) is $1 / 2$ of the total number of games played, ${ }^{27}$ and $1 / 4$ terminate at the second term and so on. In general if $\mathrm{M}$ games are played then the number terminating at term $T_{1}, T_{2}, T_{3}, \ldots T_{i} \ldots$ is $n=p_{i} \cdot M$. This number is then multiplied by the payout $\mathrm{C}_{\mathrm{i}}$ for that term and divided by the total number of games played, M. In this way the contribution of each individual term to the EMV is established. The various contributions are then summed to arrive at the EMV.

If the game is played $2{ }^{\mathrm{k}}$ times, the number ${ }^{28}$ of $\left(\mathrm{n}_{1}\right)$ games which terminate after the first flip of the coin is $1 / 2 \times 2^{k}$ or $2^{\mathrm{k}-1}$. The payout for the first term $\left(\mathrm{T}_{1}\right)$ is $\$ 2{ }^{0}$. The number of $\left(\mathrm{n}_{2}\right)$ games which terminates after the second flip, $\left(\mathrm{T}_{2}\right)$ is $1 / 2^{2} \times 2^{\mathrm{k}}$ or $2^{\mathrm{k}-2}$ with a payout of $\$ 2^{1}$ and so the pattern continues until $2^{0}$ is reached. The results are shown in Table 2. 


\section{Table 2 The EMV of the St Petersburg game played $2^{\mathrm{k}}$ times}

\begin{tabular}{|c|c|c|c|c|c|c|c|c|c|c|}
\hline Term & $\mathbf{T}_{1}$ & $\mathbf{T}_{2}$ & $\ldots$ & $\mathbf{T}_{\mathbf{k}}$ & $\begin{array}{c}\text { Sub } \\
\text { Total }\end{array}$ & $T_{k+1}$ & $\mathbf{T}_{\mathrm{k}+2}$ & $\mathbf{T}_{k+3}$ & .. & $\begin{array}{l}\text { Totals } \\
\text { (EMV) }\end{array}$ \\
\hline Payout $\left(\mathrm{C}_{\mathrm{i}}\right)$ & $2^{0}$ & $2^{1}$ & $\ldots$ & $2^{\mathrm{k}-1}$ & ... & $2^{\mathrm{k}}$ & $2^{\mathrm{k}+1}$ & $2^{\mathrm{k}+2}$ & $\ldots$ & \\
\hline $\mathrm{n}_{\mathrm{i}}$ & $2^{\mathrm{k}-1}$ & $2^{\mathrm{k}-2}$ & $\ldots$ & $2^{0}$ & $2^{\mathrm{k}}-1$ & 0 or 1 & 0 or 1 & 0 or 1 & 0 or 1 & $2^{\mathrm{k}}$ \\
\hline $\begin{array}{l}\text { Contribution } \\
\text { to EMV } \\
\left(\mathrm{n}_{\mathrm{i}} \cdot \mathrm{C}_{\mathrm{i}} / 2^{\mathrm{k}}\right)\end{array}$ & $2^{-1}$ & $2^{-1}$ & $2^{-1}$ & $2^{-1}$ & k. $2^{-1}$ & 0 or $2^{0}$ & 0 or $2^{1}$ & 0 or $2^{2}$ & $\ldots$ & $\mid \begin{array}{c}\mathrm{k} / 2+(0 \text { or } 1) \\
+(0 \text { or } 2) \\
+(0 \text { or } 4) \\
+\ldots\end{array}$ \\
\hline $\begin{array}{l}\text { Probability } \\
\text { of games } \\
\text { terminating at } \\
\text { specific term }\end{array}$ & 0 & 0 & 0 & 0 & ... & $2^{-1}$ & $2^{-2}$ & $2^{-3}$ & ... & 1 \\
\hline
\end{tabular}

At the $\mathrm{k}^{\text {th }}$ term $\left(\mathrm{T}_{\mathrm{k}}\right)$ the game has been played $2^{\mathrm{k}-1}+2^{\mathrm{k}-2}+2^{\mathrm{k}-3} \ldots 1$ times. This is a geometric progression the sum of which is $2^{\mathrm{k}}-1$. In other words all games have terminated by the $\mathrm{k}^{\text {th }}$ term, except one ${ }^{29}$, which had already ${ }^{30}$ terminated at some point beyond the $\mathrm{T}_{\mathrm{k}}$ term by the time $\mathrm{M}$ games had been played.

If this solitary game ended at $\mathrm{T}_{(\mathrm{k}+1)}$ the payout is $\$ 2^{\mathrm{k}}$ and the contribution to the EMV is $\left(\$ 22^{k} .2^{-k}\right)=\$ 1$. Since all the $2^{\mathrm{k}}$ games have now terminated all other terms in the series equals zero, all the way to infinity. If the remaining game terminated at $\mathrm{T}_{(\mathrm{k}+2)}$ then the payout for this game is $\$ 2{ }^{\mathrm{k}+1}$ and the contribution to the EMV from this game is $\left(\$ 2{ }^{\mathrm{k}+1} \cdot 2^{-\mathrm{k}}\right)=\$ 2$. In this event the contribution from $\mathrm{T}_{(\mathrm{k}+1)}$ term is 0 as are all the other terms to infinity. Thus although terms beyond the $\mathrm{k}^{\text {th }}$ term have both payouts ${ }^{31}$ and a priori probabilities $\mathrm{p}_{\mathrm{i}}$, the contribution from all of these except one, equals zero, since all games had ended. The contribution of this final game, to the EMV depends on its position after the $\mathrm{k}^{\text {th }}$ term.

Thus using a priori $^{32}$ probabilities when the St Petersburg game is played 2 times it produces, with certainty a series consisting of not more than $\mathrm{k}+1$ terms, with the series terminating beyond the $\mathrm{k}^{\text {th }}$ term. If played a finite number of times, a finite, not infinite series is produced. The probability of there being less than $\mathrm{k}$ terms is thus zero. After the $\mathrm{T}_{\mathrm{k}}$ term the series can terminate at any term to infinity. However each term beyond $\mathrm{T}_{\mathrm{k}}$ requires an additional flip of the coin, with a probability of $1 / 2$. The probability thus of the term ending after the $T_{k}$ term, decreases at the rate $1 / 2$. In other words the probability of terminating at $\mathrm{T}_{\mathrm{k}+1}$ is $1 / 2$ at $\mathrm{T}_{\mathrm{k}+2}$ is $1 / 4$, at $\mathrm{T}_{\mathrm{k}+3}$ is $1 / 8$, at or beyond the $\mathrm{k}+4$ is $1 / 16$, adding 1,2 , 
$4,8 \ldots$ to the EMV arrived at by summing the contributions to the EMV up to the $T_{k}$ term. It is clear that the series beyond the $T_{k}$ term is once again the same series as for a single game. As indicated above a reasonable man would value this at an amount of approximately $\$ 8$.

The EMV of the St Petersburg game, played $2{ }^{k}$ times and which pays $\$ 1$ if a head appears on the first flip of the coin can now be stated.

$\operatorname{EMV~}\left(2^{\mathrm{k}}\right)=\mathrm{k} / 2+\left[(1 ; 1 / 2)\right.$ or $(2 ; 1 / 4)$ or $\left(2^{2} ; 1 / 8\right)$ or $\left(2^{3} ; 1 / 16\right)$ or $\left.\ldots 8 ; 0\right]$ and if $?=\left[(1 ; 1 / 2)\right.$ or $(2: 1 / 4)$ or $\left(2^{2} ; 1 / 8\right)$ or $\left.\left(2^{3} ; 1 / 16\right) \ldots\right]$ then: $\operatorname{EMV}\left(2^{k}\right)=\frac{k}{2}+\lambda$

with the lowest value of the EMV being $\mathrm{k} / 2+1$.

or for all practical purposes:

$\operatorname{EMV}\left(2^{k}\right) \approx \frac{k}{2}+8$ at a 93.7 per cent confidence level.

The St Petersburg game thus does not have a single a priori value for the EMV. It has a series of possible EMVs starting at $\mathrm{k} / 2+1$ and continuing to infinity with decreasing probabilities. Of course for any specified number of games, the empirical EMV will have only one value determined by the above equation.

The traditional solution EMV $=\infty$ is correct but only where the St Petersburg game is played an infinite number of times.

Many people may, subconsciously if nothing else, hold the view that the EMV, is the aggregate of the payouts divided by the number of games played (M), in the limit, when $\mathrm{M}$ approaches infinity. In terms of this view there is only one EMV and that is the value derived when the numbers of games tend to infinity. Those who hold this view will then hold that the traditional solution to the St Petersburg game that the EMV is infinity is correct by definition. There is no problem with this view but it still does not produce a paradox. One must compare apples with apples. If the assumption is that the game is played an infinite number of times, then it must be accepted that Paul can play the game an infinite number of times. In other words the question is 'Paul plays the St Petersburg game an infinite number of times, how much should he be prepared to wager per game to do so?' The answer to this question is quite correctly an infinite amount. 
One cannot compare apples with pears. It clear that the traditional question is irrational if stated as, 'Paul plays the game a finite number of times (M), why does he not wager a substantial amount to play the game?' The answer is of course because he is only playing the game a finite number of times. In the traditional formulation of the paradox, the assumption is that Paul plays the game only once but then uses the EMV of an infinite number of games. It is not comparing apples with apples.

Returning to the above example. Assume Paul decides he will play one game for $\$ 8$. Should Peter accept the wager? Peter needs to know how many other games will be played at his casino ${ }^{33}$. Assume he accepts the $\$ 8$ from all the Pauls and estimates that during the next financial year his casino will play $2^{20}$ (i.e. 1048 576) games. The question now is, will he face a loss at the end of the year from all of these games? The EMV of these games ${ }^{34}$ is $\$ 10+(\$ 1$ or $\$ 2$ or $\$ 4$ or $\$ 8$ ) ie within realistic confidence limits from $\$ 11$ to $\$ 18$. The first point to note is that whatever figure is chosen it is a modest amount, nowhere near the say $\$ 10 \mathrm{~m}$ or more required by the traditional solution to the St Petersburg game. The second point is using a priori probabilities Peter faces certainty that the EMV will not be less than $\$ 11$. In other words if he accepted $\$ 8$ from all the Pauls he would have lost not less than $\$ 3$ per game or a total certain loss of not less than \$3 146328 pa. What Peter should have charged was not less than $\mathrm{k} / 2$ + ? or $\$ 18$ to be 93.75 per cent confident that he would not suffer a loss.

\section{CONCLUSION}

So it is easy to answer the question, 'How much should the reasonable man, Paul, be prepared to pay to play the St Petersburg game?' Paul would simply respond, 'How many times am I allowed to play the game?' If the answer is twice he would answer, 'An amount in the order of $\$ 1 / 1+\$ 8=\$ 9$.' If the answer is that he can play the game $2^{18}$ times he would answer, 'An amount in the order of $\$ 9+\$ 8=\$ 17$.' It will be noted that although the number of games increase substantially, the size of Paul's wager does not. In all cases the amount the EMV, once correctly determined, predicts that his wager is moderate and this is in accordance with common experience. If the answer is that he can play an infinite number of games, his answer would be that he would wager an infinite amount.

The correct determination of the EMV does not thus expect Paul to wager an infinite amount to play a finite number of games, nor would a reasonable person do so. The EMV once correctly derived for the St Petersburg game does not lead to a paradox at all - it never did. The application of the EMV criterion gives an answer that is consistent with the behaviour of the reasonable man. 
Traditionally the incorrect value of the EMV was used. Utility (cardinal or ordinal) is not required to explain the behaviour of Paul - he has during all these centuries been quite rational after all.

\section{ENDNOTES}

1 Earlier drafts of this paper were presented at a Business Economics Research Group of the University of the Witwatersrand and at the 12th Annual Conference of the South African Institute for Management Scientists 31st October-2nd November 2000. The paper has benefited from comments and advice from a number of academics from various parts of the world. The usual disclaimers apply.

2 For a history, including the treatment of the paradox by mathematicians of the previous centuries see Samuelson (1977). Some of the more recent writers who accept that the EMV of the St Petersburg game is infinite or the utility solution to the paradox include Todhunter (1949/1865: 220); Marshall (1920: 134); Keynes (1973/1921: 350); Von Neumann and Morgenstern (1953); Friedman and Savage (1948: 281 and note 5); Stigler (1950: 374); Arrow (1951: 407); Menger (1954, note 9) published in Bernoulli (1954/1738); Samuelson (1960); Borch (1968,15); Savage (1972: 93); Arrow (1974: 63); Brito (1975: 123); Sennetti (1976); Shapley (1977: 439); Epps (1978); Hagen published in Allais and Hagen (1979: 14); Gorovitz (1979: 259); Allias (1979: 498); Székely (1987: 28); Bassett (1987: 517); Cowen and High (1988: 199); Machina (1987: 50); Russon and Chang (1992: 8); Schmeidler and Wakker (1996); Starmer (2000); Aase (2001).

3 Bernoulli's paper was presented in 1731 but only published in 1738 however the St Petersburg game was formulated in 1728.

$4 \quad$ Von Neumann and Morgenstern's (1953) book sparked off the renaissance in cardinal utility theory. The literature on cardinal utility is immense but fortunately for purposes of this paper it is not necessary to discuss cardinal utility since it is the thesis of this paper that the St Petersburg paradox can be resolved without resorting to utility theory. For a review of the current position see Schoemaker (1982), Machina (1987) and Starmer (2000).

5 A number of explanations have been given as to why the game is called the St Petersburg game. Samuelson (1977: 36 note 1) suggests it is because Bernoulli's article appeared in St Petersburg. Savage (1972: 93) ascribes the name to the journal in which Bernoulli's paper was first published. Slight variations in the name are encountered. Some writers such as Keynes (1973/1921: 349) refer to the paradox as the Petersburg paradox.

6 I say now because until Samuelson (1977) set-out its history this had not 
really been done or as Samuelson put it '... I found to my surprise that no one seems to have provided anything like a complete survey of the subject.' Earlier writers in particular Todhunter (1865) provided at least an outline of the subject.

7 The theory could have more than one emphasis. It can for example attempt to explain the behaviour of people when faced with decisions involving uncertainty or be a management tool to assist in making an appropriate decision.

8 The EMV is derived as follows. If a game of chance is played $\mathrm{M}$ times and has a range of possible outcomes $\mathrm{C}_{1}, \mathrm{C}_{2}, \mathrm{C}_{3} \ldots \mathrm{C}_{\mathrm{M}}$ then the $E M V_{M}=\frac{1}{M} \sum_{i=1}^{i=M} C_{1}$. Where the outcomes fall into categories and the number of times that an outcome appears in each category is $n_{1}, n_{2}, n_{3}, \ldots n_{J}$, then the $E M V_{M}=\sum_{i=1}^{i=J} \frac{n_{i}}{M} \cdot C_{i}$. Where $\mathrm{M}$ is large, the corresponding probabilities become $\mathrm{p}_{1}, \mathrm{p}_{2}, \mathrm{p}_{3}, \ldots \mathrm{p}_{\mathrm{J}}$ then the $E M V \infty=\sum_{i=1}^{i=J} p_{i} C_{i}$. Implicit in the idea of the EMV is that $\mathrm{M}$ is large, indeed the EMV is often defined as the value when $\mathrm{M}$ tends to infinity ie $E M V_{\infty}=\int_{-\infty}^{+\infty} p(x) \cdot C(x) \cdot d x$ for continuous distribution.

9 Samuelson (1977: 37 n4) points out that crediting Pascal and de Fermat underplays the rôle of earlier contributors.

10 I have used the term reasonable person, the same term used by Daniel Bernoulli, to avoid a debate if this reasonable person is rational or risk averse or risk neutral or risk seeking. It can of course be argued, as Bernoulli did, that no gambler is rational.

11 Bernoulli did not claim to be the originator of the game. Nicolas Bernoulli appears to have first suggested the game.

12 Marshall (1920: 134 et seq) preferred using income rather than wealth as a measure of utility. Income is not however in issue when it comes to investment decisions where "something" is risked. It is capital (what Marshall referred to as stock of wealth) not income, which is risked when undertaking risky projects. See also Friedman and Savage (1948) for the use of income instead of wealth.

13 The original currency was the ducat, which Bernstein (1998: 106) equates to about $\$ 40$ today. In principle the type of currency is irrelevant. This paper uses dollars.

14 It is accepted that the typical gambler would be prepared to pay an amount in excess of the mathematical expectation of a game of chance.

15 There is a further problem with the traditional solution. In the limit as the payouts tend to infinity and the probability of these large payout tends to 
zero and the contributions from this point onwards, strictly speaking become which is $1 / 2^{\mathrm{n}-1} \cdot 2^{\mathrm{n}}$ or 0.4 which is indeterminate and not a constant.

16 Assume for example the game continues to a payout of $2^{100}$ an enormous amount. The probability of this happening is $2^{-101}$ and hence, according to the traditional view the contribution of this term is still only $1 / 2$. The size of the final payout is irrelevant in the determination of the EMV.

17 I have often explained the game to students and asked them to indicate the amount they would be prepared to risk to play the game. No student is ever prepared to risk more than a few dollars to play the game. Despite going to great lengths to explain the game I doubt if every student understood the explanation since some students indicate that zero is a reasonable amount to play the game. Since the lowest amount to be won is $\$ 1$, it is clear that those students did not comprehend the game.

18 Utility solutions do not, of course, try to reconcile the EMV criterion and the paradox. They do the very opposite and look for an alternative solution to the paradox, accepting that the EMV cannot explain the paradox. Cardinal utility solutions to decisions under uncertainty are increasingly coming under attack, see Starmer (2000); Rabin and Thaler (2001).

19 For a discussion of a single game of the St Petersburg game consult Allais (1979: 501 et seq).

20 Allais (1979: 502) concludes that 'the rule of mathematical expectation cannot be a rational principle for decision taking in the case of a single game.' He concludes that $\$ 33$ dollars would be the amount a syndicate would offer to play a single came if the banker's (casino owner) wealth is \$10bn.

21 The various writers arrived at their conclusion for different reasons. Daniel Bernoulli (1954/1738: 32) accepted an amount of 2 ducats if Paul had no initial wealth, Nicolas Bernoulli, his cousin (or uncle) accepted an amount of less than 20 ducats. Gabriel Cramer, in 1728 accepted an amount of less than 20 ducats. Arrow $(1974,407)$ accepts that Paul will not pay the predicted large amount. Sennetti (1976: 960) accepts an amount of less than \$10. Allais (1979: 502) postulates an amount less than $\$ 33$ where a single game is played.

22 This is almost invariably the answer I get from at least one student when I ask a class of students the question, 'How much would you be prepared to pay to play one round of the St Petersburg game?'

23 I say only one because if it goes to infinity it never ends and thus the next game in the series will never be played.

24 I simulated St Petersburg games millions upon millions of times; all ended. An academic commenting on an earlier draft of this paper simulated the game a billion times; all ended. In practice the games end. 
25 See in particular see footnotes 29 and 30.

26 Many writers think that time is a factor which limits the game. It is not clear why they believe that time is an issue. In order to win $\$ 2^{100}$, only 98 tails in a row would be required, even if played manually this game would take less than five minutes to complete.

27 Bernoulli confused matters slightly by saying an infinite number of games are played. This being so Karl Menger, in footnote 10 in Bernoulli's (1954/1738) paper correctly pointed out that it is not possible to divide infinity by $1 / 2$ or a $1 / 4$ etc.

28 Strictly speaking, $\mathrm{n}_{\mathrm{i}}$ is the '... probable number of times that the game terminates...'

29 The implications of this statement must be understood. If the game is played $2^{\mathrm{k}}$ times it is certain that there will be $2^{\mathrm{k}}-1$ games all of which terminate by the kth term. In other words the idea that the St Petersburg game continues to infinity is not only wrong in practice it is wrong in theory. Only one game can continue beyond the kth term.

30 The game which terminates beyond the $T_{k}$ term could be any one of the $M$ games. By the time the last game is played, the game which survives beyond the $T_{k}$ term is almost certain to have long already have ended. The idea that the last game which is played will also somehow be the game which continues to infinity can be dismissed as a statistical improbability.

31 The fact that all terms have a payout is relevant to Menger's superparadoxes (see Samuelson (1977)). It does not matter what values are assigned to the payouts if $\mathrm{n}_{\mathrm{i}}$ is zero. Neither the a priori probabilities nor payouts matter if all games have ended.

32 It is possible to simulate the games in which event ni will only approximate pi .M. In this case it is possible to get more or less than one game terminating beyond Tk.

33 It is not unusual that the two parties to a transaction involving risk are in a different position. A person seeking insurance for his house faces a low frequency of the destruction of his house, say 1/10 000 per annum. Most insureds will not in their lifetime experience a total loss. The insurer on the other hand which insures say 1000000 houses, faces a virtual certainty that at least more than one insured house will be destroyed each year and more likely than not 100 houses a year will be destroyed.

34 Derived from the formula developed in this paper.

\section{REFERENCES}

1 AASE, K.K. (2001) "On the St Petersburg Paradox", Scandinavian Actuarial Journal: 69-78.

2 ALLAIS, M. (1979) "The Allais 1952 Theory of Choice with 
Uncertainty" in Expected Utility Hypotheses and the Allais Paradox, M Allais and O Hagen (eds.) Dordrecht, D Reidel Publishing Company.

3 ALLAIS, M. \& HAGEN, O. (1979) (eds.) Expected Utility Hypotheses and the Allais Paradox, Dordrecht, D Reidel Publishing Company.

4 ARROW, K.J. (1951) "Alternative approaches to the theory of choice in risk-taking situations", Econometrica, 19: 404-37.

5 ARROW, K.J. (1974) Essays in the Theory of Risk-Bearing, NorthHolland ( $2^{\text {nd }}$ printing).

6 BASSETT, G.W. (1984) "The St Petersburg paradox and bounded utility", History of Political Economy, 19(4): 517-23.

7 BERNOULLI, D. (1954/1738) "Exposition of a new theory on the measurement of risk" Econometrica, 22(1): 23-36.

8 BERNSTEIN, P.L. (1998) Against the Gods - the remarkable story of risk, John Wiley \& Sons

9 BORCH, K.H. (1972/1968) The Economics of Uncertainty, Princeton: Princeton University Press [1968] 1972 reprinting.

10 BRITO, D.L. (1975) "Becker's Theory of the Allocation of Time and the St Petersburg Paradox" Journal of Economic Theory, 10(1): 123-6.

11 COWEN, T. \& HIGH, J. (1988) "Time, bounded utility, and the St Petersburg Paradox", Theory and Decision, 10: 219-23.

12 EPPS, T.W. (1978) "Financial Risk and the St Petersburg Paradox: Comment" Journal of Finance, 33: 1455-56.

13 FRIEDMAN, M. \& SAVAGE, L. (1948) "The Utility analysis of choice involving risk", The Journal of Political Economy, 56: 279-304.

14 GOROVITZ, S. (1979) "The St Petersburg Puzzle" in Expected Utility Hypotheses and the Allais Paradox, M Allais and O Hagen (eds.) Dordrecht, D Reidel Publishing Company.

15 KEYNES, J.M. (1973/1921) A Treatise on Probability, London: Macmillan Press Ltd, The Royal Economic Society Edition [1921].

16 MACHINA, M.J. (1987) "Choice under uncertainty: Problems solved and unsolved" Journal of Economic Perspectives, 1: 121-54.

17 MARSHALL, A (1920) Principles of Economics ( $8^{\text {th }}$ ed.) MacMillan \& Co, London 1947 reprint.

18 MENGER, K. (1954) in Bernoulli, Daniel. (1954/1738) "Exposition of a new theory on the measurement of risk", Econometrica, 22: 23-36.

19 RABIN, M. \& THALER, R.H. (2001) "Anomalies: Risk aversion", The Journal of Economic Perspectives, 15: 219-32.

20 RUSSON, M.G. \& CHANG, S.J. (1992) "Risk aversion and practical expected value: A simulation of the St Petersburg Game”, Simulation \& Gaming, 23: 6-19.

21 SAMUELSON, P.A. (1960) "The St Petersburg Paradox as a divergent double limit", International Economic Review, 1: 31-7.

22 SAMUELSON, P.A. (1977) "St Petersburg Paradoxes: Defanged, 
dissected and historically described", Journal of Economic Literature, 15: 24-55.

23 SAVAGE, L.J. (1972) The Foundations of Statistics, (2 ${ }^{\text {nd }}$ ed.) New York, Dover Publications Inc. (rev. ed.)

24 SENNETTI, J. (1976) "On Bernoulli, Sharpe, financial risk and the St Petersburg Paradox", The Journal of Finance, 31: 960-62.

25 SCHMEIDLER, D. \& WAKKER, P. (1996) "Expected utility and mathematical expectation", The New Palgrave - A dictionary of Economics, MacMillan Press: 229.

26 SCHOEMAKER, P.J.H. (1982) "The Expected Utility Model: Its Variants, Purposes, Evidence and Limitations", Journal of Economic Literature, 20: 529-36.

27 SHAPLEY, L.S. (1977) "The St Petersburg Paradox: A con game", Journal of Economic Theory, 10: 439-42.

28 STARMER, C. (2000) "Developments in non-expected utility theory: The hunt for a descriptive theory of choice under risk", Journal of Economic Literature, 38(2): 332-82.

29 STIGLER, G.J. (1950) "The development of utility theory II", The Journal of Political Economy, 58: 373-96.

30 SZÉKELY, G.J. (1986) Paradoxes in Probability Theory and Mathematical Statistics, Dordrecht, D Reidel Publishing Company.

31 TODHUNTER, I. (1949/1865) A History of the Mathematical Theory of Probability - from the time of Pascal to that of Laplace, New York: Cambridge University Press 1865. Reprint. New York: Chelsea Publishing Company.

32 VON NEUMANN, J. \& MORGENSTERN, O. (1953) The Theory of Games and Economic Behaviour ( $3^{\text {rd }}$ ed.) Princeton. Princeton University Press. 